\title{
ОСНОВНЫЕ ИСТОРИЧЕСКИЕ ЭТАПЫ АРХИТЕКТУРНО-ГРАДОСТРОИТЕЛЬНОГО РАЗВИТИЯ г. СОЧИ (XIX - ПЕРВАЯ ПОЛОВИНА XX В.)
}

\section{О. С. Субботин ${ }^{1}$}

\author{
${ }^{1}$ Кандидат архитектуры РФ, доктор архитектуры РА, доцент, профрессор кафедры архитектуры \\ учреждения образования «Кубанский государственный аграрньй университет имени И. Т. Трубилина», Краснодар, Россия
}

\section{Рефрерат}

Рассмотрены исторические этапы развития и становления г. Сочи XIX - XX вВ., а именно его архитектурно-пространственной структуры, в контексте ценностных характеристик среды жизнедеятельности. Значительное внимание уделено роли территориального планирования города в решении проблем, связанных с данной структурой. Представлены значимые объекты архитектурного наследия, являющиеся важными культурно-историческими ценностями города. Отмечена необходимость и целесообразность сохранения указанного наследия. Обозначена стратегия планировочного развития города с учетом сохранения исторической преемственности.

Ключевые слова: наследие, планирование, среда жизнедеятельности, потенциал, культура, архитектура.

\section{THE MAIN HISTORICAL STAGES OF ARCHITECTURAL AND URBAN DEVELOPMENT OF SOCHI (XIX - FIRST HALF OF XX CENTURIES)}

\section{Abstract}

\section{O. S. SUBBOTIN}

The historical stages of development and formation of the city of Sochi in the XIX - XX centuries, namely its architectural and spatial structure, are considered in the context of the value characteristics of the living environment. Considerable attention is paid to the role of territorial planning of the city in solving problems related to this structure. Significant objects of architectural heritage that are important cultural and historical values of the city are presented. The necessity and expediency of preserving this heritage is noted. The strategy of planning development of the city is outlined, taking into account the preservation of historical continuity.

Keywords: heritage, planning, living environment, potential, culture, architecture

\section{Введение}

Исторический город по-своему красив своей неповторимой атмосфрерой и большой притягательной силой «культурной памяти» - связь и преемственность прошедших поколений. Данная память непосредственно фиксирует в себе исторические процессы жизнедеятельности, совмещая при этом старое и новое, архитектурно-историческую и современную среду, являясь в тоже время прочной основой зарождения поселения, посредством которой происходило планировочное развитие города. Ключевая проблема указанных поселений - сохранение исторического облика культурного наследия, фоновой и средовой застройки, которые во многом определяют формирование комфортной среды жизнедеятельности.

Город Сочи обладает уникальным историко-культурным наследием. Протяженность территории исторического поселения регионального значения Сочи составляет 22,5 км. Она включает в себя не только ценные объекты культурного наследия - градостроительные ансамбли, отдельные здания и сооружения, но и малые архитектурные объекты, а также исторические панорамы.

Вместе с тем, в настоящее время стремительный процесс урбанизации временами приводит к необоснованному изменению пространственной структуры городских и сельских поселений, к несоответствию старой и новой застройки в пространственной организации города, нарушая неповторимый архитектурно-художественный облик населенного места. Поэтому тема данного исследования, посвященная исследованию архитектурно-пространственной организации г. Сочи на основе анализа территориально-планировочных планов в исторической ретроспективе его существования, является актуальной и своевременной. Более того нами определена недостаточность исследований, формирующихся на интегральной оценке территориальной организации Сочи со взаимосвязанным архитектурно-планировочным развитием поселения в исторический период XIX-XX вв.

Цель исследования состоит в выявлении особенностей архитектуры Сочи как пространственного проявления культур XIX - первая половина XX вв.

Основные задачи исследования заключаются: в выявлении аспектов, повлиявших на формирование архитектурно-пространственных особенностей города на протяжении исторических этапов его развития определении периодов указанного развития, квалифицирующих определенные тенденции своего времени, которые в целом отражали эволюцию среды жизнедеятельности исследуемого города; характеристике наиболее значимых объектов архитектурного наследия.
Объектом исследования является архитектурная среда, функционально-планировочная структура городского пространства Сочи.

Предмет исследования - закономерности и принципы организации планировочной структуры Сочи с точки зрения пространственных и архитектурных особенностей данного поселения.

Методы исследования представляют собой комплексный подход, который базируется на основе: источниковедческого анализа, включающего изучение и систематизацию архивных источников, материалов по историографии, культурологии и др. документов, а также историкотеоретических исследованиях отечественных и зарубежных ученых; сопоставительного анализа планировочной структуры города в обозначенные периоды архитектурного формирования. Сочи

Предпосылки историко-градостроительного формирования

«Стратегический фрактор» сыграл основополагающую роль в истории становления и формирования Сочи. Особенно следует отметить историческую значимость береговых военных укреплений XIX в., возведенных на территории современного Большого Сочи (районы: Центральный, Адлерский, Лазаревский, Хостинский и Красная Поляна), предназначенных для охраны границ Российской империи. При этом выбор места для возведения данных укреплений был продиктован природными условиями местности и обусловлен ее защитными свойствами.

Первым оборонительным сооружением, возведенным русскими войсками в 1837 г., было фортификационное укрепление Святого Духа (нынешний Адлер) в устье реки Мзымта. Затем в 1838 г. был заложен форт Александрия, который впоследствии из-за схожести названия с другими укреплениями Черноморского побережья в 1839 г. был переименован в Навагинский и в этом же году были построены отдельные оборонительные укрепления - форты на реке Псезуапсе - Лазарев (Лазаревское) и на реке Шахе - Головинский (Головинка) (рисунок 1-2).

Водная гладь Черного моря, ландшафтное окружение, горный рельеф особенно ярко подчеркивали художественно-эстетическую выразительность облика данных сооружений, которые представляли собой уникальные произведения оборонного зодчества. К сожалению, с течением времени фортификационные сооружения Черноморского побережья в первозданном виде не сохранились, остались лишь фрагменты крепостных стен. Вместе с тем данные сооружения особо ценны не только как историческая информация, представляющая большой интерес как напоминание об определенных событиях прошлого, но и как память благодарных потомков. 


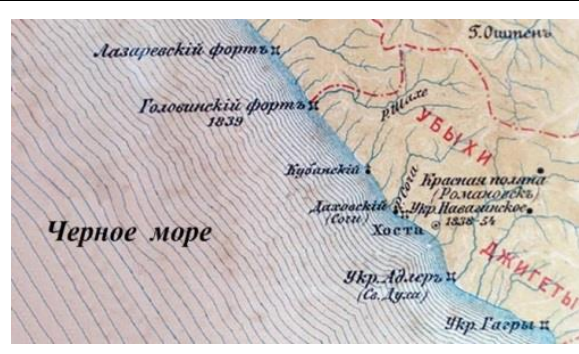

Рисунок 1 - Карта фортификационных укреплений в районе Сочи, 1830-е гг.

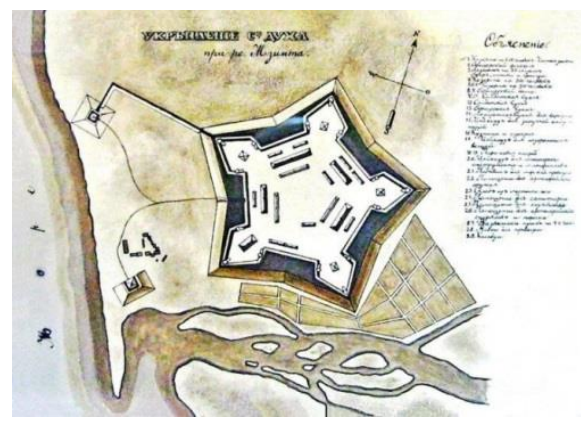

a)

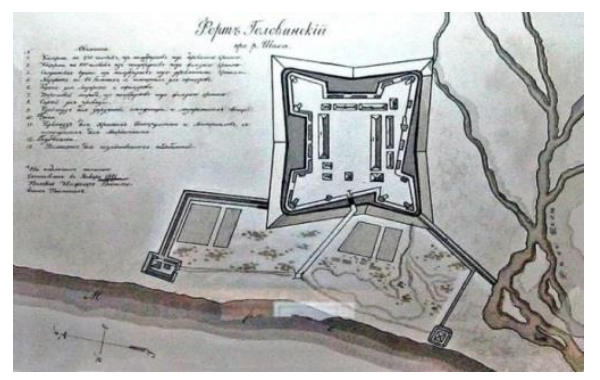

б)

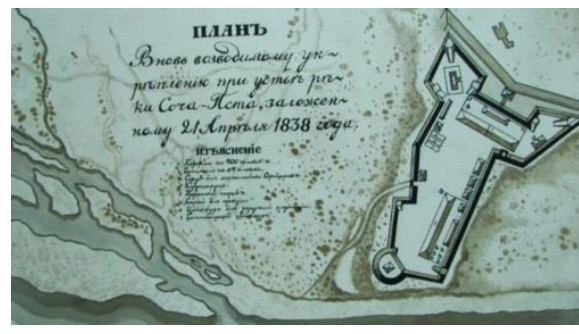

B)

а) Укрепление Святого Духа (1837 г.); б) форт Гловинский (1839 г.); в) форт Александрия (1838 г.)

Рисунок 2 - Планировочные схемы фортификационных укреплений в районе Сочи, 1830-е гг.

Исследование предпосылок становления поселения Сочи как одного из важных стратегических центров Черноморского побережья позволило определить, что планировочная структура фортификационных сооружений была выполнена в четкой и довольно строгой последовательности необходимых членений и в ритмическом построении наблюдательных башен. В большинстве своем фортификационные укрепления имели оригинальную архитектурную форму в виде многолучевой звезды.

Следует также отметить, что возведение указанных укреплений способствовало сложению гражданских посадов, что и предопределило дальнейшее развитие системы посадского и затем городского расселения со своей специализацией народного хозяйствования. Все лучшее из опыта военного искусства в строительстве укреплений и методов возведения построек жилого, хозяйственного и культового назначения воплощалась в планировочной структуре будущих городов, в функциональном зонировании территорий.
Типологические особенности эволюции архитектурнопланировочной структуры Сочи (вторая половина XIX - начало $\mathrm{XX}$ B.)

Во второй половине XIX в. большую роль в направлении пространственной организации Сочи играла уже сложившаяся территориально-планировочная структура фортификационных сооружений, природно-ландшафтное окружение и водные объекты. Наряду с этим на концентрацию населения на той или иной осваемой территории, а также на эволюцию пространственной структуры указанного населенного места повлияли также политические, градостроительные, социально-экономические, демографические и административные факторы. При этом, планировочная структура Сочи складывалась, видоизменялась и трансформировалась в процессе длительного архитектурно-градостроительного развития населенного места. Поэтому разрешение ряда специфических архитектурно-градостроительных проблем невозможно без анализа исторических закономерностей становления города и его последующего развития.

Наиболее интенсивное историческое развитие городского расселения и территориальной организации пространства Сочи в контексте формирования своеобразной градостроительной архитектуры в городе пришлось на период XIX-XX вв.

В 1864 г. десант русских военных кораблей, высаженный в устье р. Сочи, и Даховский отряд под командованием генерала В. А. Геймана совместными усилиями заняли развалины Навагинского форта и превратили его в крепость, получившую название «пост Даховский». Через два года, 10 марта 1866 г., императором Александром II было утверждено «Положение о заселении Черноморского округа и управления оным», которое регламентировало гражданское государственное строительство в данном районе и в частности на территории Сочи.

В 1874 г. пост Даховский преобразуется в посад Даховский. С этого времени и начинается история посада Даховского, еще в то время неофициально именуемого посадом Сочи, ставшего в последствии городом-курортом Сочи [1, с. 26]. Даховский посад представлял собой посад Черноморской губернии, на берегу Черного моря, при устье речки Сочи. C севера и северо-востока посад защищен отрогами Кавказского хребта, покрытыми густыми лесами. Жителей 1309 (женщин всего 462), из них: коренных 91, пришлых 1118 и иностранцев 190. Православная церковь 1, 145 домов, 55 торговых заведений, бойня, больница на 8 кроватей [2].

Из приведенной численности населения следует, что коренное население было в меньшинстве, большую часть составляли этнические группы, проживающие на данной территории.

Вместе с тем, несмотря на живописное местоположение посада и благодатные природно-климатическим особенности, территориальнопространственная структура населенного места и его элементы были построены по упрощенной схеме. Первоначально посад состоял из нескольких дворов и не отличался разнообразием планировочных связей.

Следующим промежуточным этапом в историко-градостроительном развитии Сочи был временной период, охватывающий 1891-1893 гг., когда вдоль Черноморского побережья осуществлялась прокладка шоссе Новороссийск - Сухум, которое стало главной планировочной осью, связывающей многочисленные населенные пункты, повысив тем самым показательность застройки территорий. Это непосредственно отразилось на хозяйственной деятельности поселений, во многом способствовало территориальному планированию, создавая благоприятные условия для устойчивого развития близлежащих поселений.

25 мая 1896 г. Государственный Совет рассмотрел представление председателя высочайше учрежденной Особой комиссии для выработки проекта законоположений по устройству Черноморского побережья и о преобразовании административного устройства Черноморского округа и постановил образовать Черноморскую губернию, разделив ее на три округа: Новороссийский, Туапсинский, Сочинский, а управлением названной губернии назначить город Новороссийск. В конце XIX в. Сочинский округ по своим размерам превышал территорию современного Большого Сочи. В 1898 г. посад Сочи был включен в перечень поселений с упрощенным общественным управлением, а именно входил в разряд поселков городского типа.

Предприниматель Г. Г. Москвич, с 1988 г. по 1913 г. организовавший туристические экскурсии по Кавказу, отмечает: «Сочи - 
Вестник Брестского государственного технического университета. 2021

небольшой городок Черноморского побережья, один из тех, которые в последнее время стали привлекать к себе общее внимание как местность, имеющая, благодаря счастливо сложившимся природным условиям, все данные, чтобы сделаться первоклассным климатолечебным и морским курортом [3, с. 371] (рисунок 3,a).

К началу 1900 г. по характеру поселения г. Сочи условно делился на две части - верхнюю, так называемую аристократическую часть города, и прилегающую нижнюю часть, которая начиналась от Соборной улицы и тянулась до р. Сочи и была застроена в основном жилым фондом местных жителей, главным образом русских, армян, грузин и греков. Наибольший расцвет гражданского строительства в городе и его окрестностях приходился на 1901-1903 гг., когда государственным служащим было сообщено о проведении в скором времени железной дороги вдоль Черноморского побережья [4, с. 52] (рисунок 3,б).

a)

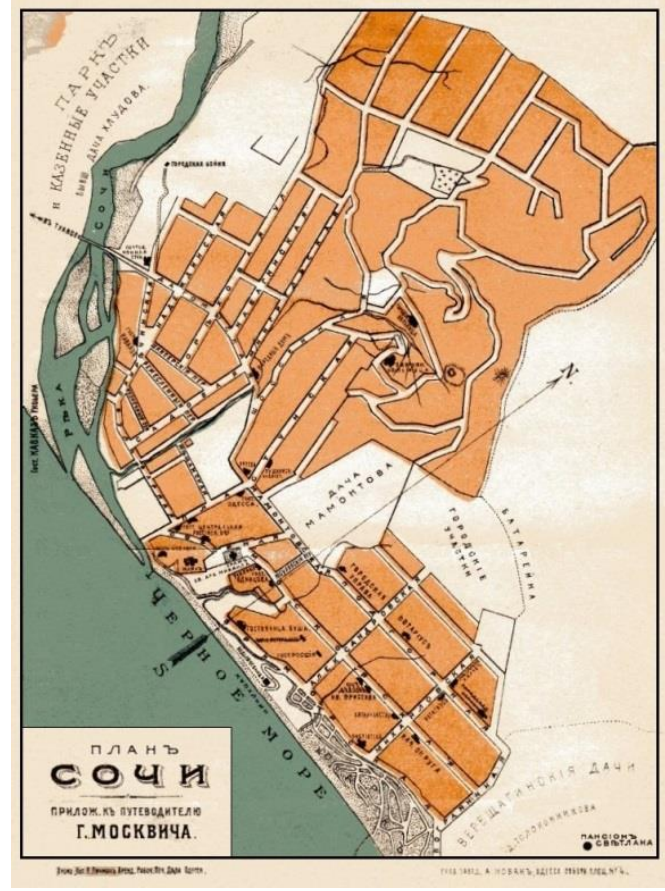

б)

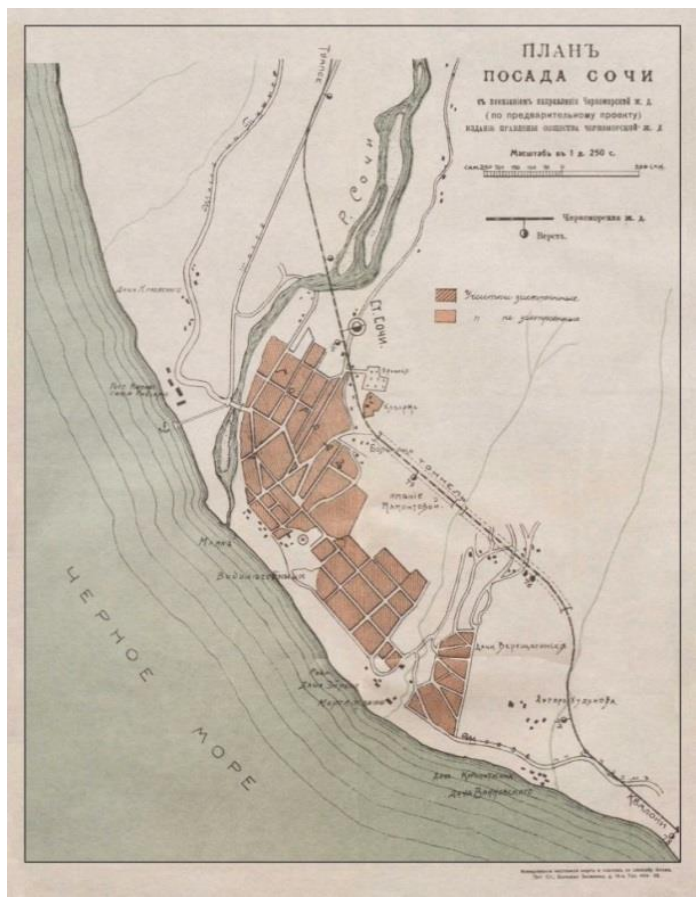

Рисунок 3 - План Сочи, начало XX в.
Отдельные улицы посада Сочи, образующие взаимосвязанную улично-дорожную сеть в планировочной структуре поселения, особенно центральная - ул. Пластунская, представляли собой единый ансамбль со своеобразной замысловатой архитектурой дачных домиков и общественных зданий в окружении зеленых насаждений, являющихся органической частью городского пространства.

Весь город утопает в зелени. Городские участки разбиты площадями не менее четверти десятины и каждый засажен декоративными растениями или сохранил в виде парка тот лес, которым была покрыта вся городская земля. При разбивке участков для продажи часть земли была оставлена под парки для общественного пользования [5, с. 54] (рисунок 4).

В то время министерство земледелия было заинтересовано в дальнейшем развитии Сочи и уделяло большое значение вопросам расселения, что естественно порождало уверенность и желание граждан приобретать земельные участки под дачи, виллы и различные постройки. Также значительное внимание Сочи уделял император Николая II, у которого были имения в местечке Дагомыс и «охотничный домик» в Красной Поляне, указывал на необходимость увеличения населения в Сочинском округе. Это сопутствовало развитию градостроительства на рубеже XIX-XX вв., в частности на деньги дворянства и купечества.

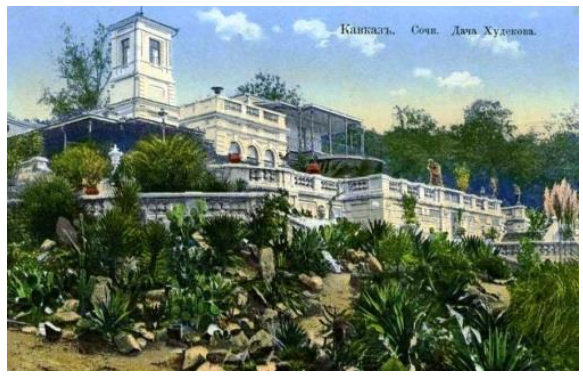

Рисунок 4 - Сочи. Дача Худекова в парке. Конец XIX - начало XX в.

Таким образом изучение динамики развития планировочной структуры Сочи второй половины XIX в. было направлено в первую очередь на выявление планировочной организации поселения, в контексте индивидуальных типологических особенностей населенного места и существующей системы объектов и комплексов в исследуемые периоды. При этом проведенный анализ указанных особенностей выявил, что характер указанной планировочной организации во многом соответствовал статусу города и его функциональному профилю.

Архитектурно-градостроительное развитие г. Сочи как городакурорта во второй половине XX в.

Историческим событием в развитии города явилось строительство курорта «Кавказская Ривьера».

Строительство курорта проводилось известным в России архитектором-художником В. И. Ионом. Здания, построенные в стиле модного тогда декадентского модерна, возвышались у самого моря. Архитектор так умело и остроумно использовал склон к морю и все свободные площадки, что получилась масса уютных уголков, засаженных тропической растительностью [6, с. 120]. Рядом с гостиничными корпусами обустроили большой парк, растения для которого выписывали из-за границы [7, с. 24].

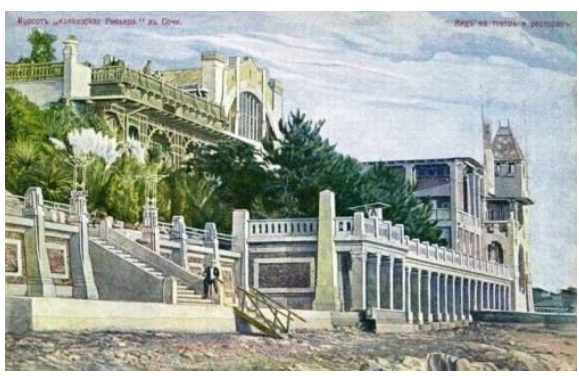

Рисунок 5 - Сочи. Курорт «Кавказская Ривьера», начало XX в. 
На данный период происходит формирование своеобразной градостроительной архитектуры, присущей только черноморским курортным городам. Распространение получил модный на тот момент европейский стиль модерн, в котором угадывались элементы крепостных стен замков. При этом следует подчеркнуть, что в архитектурных объектах Сочи отмечается пропорциональность и масштабность, монументальность и лаконичность, изящество линий, а также большое разнообразие архитектурных форм и стилей.

В первой половине XX в. основной принцип градостроительного подхода при строительстве Сочи был нацелен на создание курорта как города-сада. Архитектура носила павильонной характер, свойственный парковым ансамблям, в которой главной целью зодчих было достижении гармонии архитектуры с природным ландшафтом. Парки составляли особую гордость города-курорта Сочи [7, с. 49].

Основным решающим фактором в целенаправленном архитектурно-градостроительном развитии Сочи послужило законодательное присвоение городу 26 мая 1925 г. статуса курорта общегосударственного значения.

Начинается новая эра в градостроительном отношении Сочи, а именно преобразование крупного территориального района с целью объединения взаимосвязанных территорий для создания целостности всех его элементов. В 1930-е гг. был разработан и принят к реализации судьбоносный документ градостроительного регулирования - первый генеральный план реконструкции курорта Сочи-Мацеста. Хронологические рамки реализации данного периода составляли 25 лет. Большое внимание было уделено дорожному строительству, в частности прокладки транспортной магистрали Сочи-Мацеста-Хоста, а также возведению в данном случае многочисленных мостовых транспортных сооружений, в том числе виадуков.

\section{Заключение}

Таким образом проведенное исследование архитектурно-пространственного формирования г. Сочи, охватывающее периоды развития территориально-планировочной структуры города в хронологических рамках XIX - первой половины XX вв., позволило определить следующие основные этапы:

І этап - становление войскового поселения (1830-1860-е гг.);

II этап - становления гражданского поселения (1870-1903 гг.).

1 период - прокладка шоссе Новороссийск - Сухум (1891-1893 гг.);

2 период - строительство железной дороги (1901-1903 гг.).

III этап - становление климатолечебного и морского курорта (1904-1930-е гг.)

1 период - строительство курорта «Кавказская Ривьера» (19041909 гг.);

2 период - создание города-сада, в том числе реконструкция курорта Сочи-Мацеста (1910-1930-е гг.).

Исходя из вышеизложенного можно сделать вывод, что при решении задач градостроительного масштаба, особенно территорий исторических поселений необходимо прежде всего проводить ретроспективный анализ архитектурно-градостроительного развития поселения в различное время его образования. Указанный анализ во многом помогает определить тип сложившейся планировочной структуры населенного места, специфические природные и иные составляющие.

При этом проведенный анализ «служит базовым инструментом для выполнения градостроительных концепций устойчивого развития данного поселения, а также для формирования современной архитектурно-пространственной среды с учетом надлежащих требований к композиционной организации населенного места и к архитектурно-ландшафтным пространствам [9, с. 137].

Одновременно на основе ретроспективного анализа объемнопространственной композиции исторических центров поселений определяются ценностные характеристики среды жизнедеятельности, обусловленные архитектурно-планировочной организацией поселений, их исторически сложившейся структурой, в соответствии с традиционным образом жизни населения. Ведущее место в указанных характеристиках занимают памятники историко-культурного наследия, неповторимые произведения народного зодчества, объекты природного ландшафта и элементы их составляющие, являющиеся национальным историко-культурным потенциалом. При этом результаты исследований имеют практическую значимость для выработки градостроительной стратегии поселения, они очень важны и актуальны и являются важнейшей составляющей архитектуры и градостроительства как науки. Сохранение объектов архитектурного наследия, природного ландшасрта историко-культурной преемственности - основа дальнейшего развития среды жизнедеятельности.

\section{Список цитированных источников}

1. Гордон, К. А. Старый Сочи конца XIX - начала XX веков: Литературно-художественное издание / К. А. Гордон. - 2-е изд., испр. и доп. - Сочи: ЗАО «Дория», 2005. - 164 с.

2. Энциклопедический словарь / под ред. К. К. Арсеньева, Е. Е. Петрушевского [и др.]. - СПб. : Типография акц. общ. «Издательское Дьло», Брокгаузъ-Ефронъ, 1901. - Т. XXXIIA. - 960 с.

3. Москвич, Г. Г. Иллюстрированный путеводитель по Кавказу с приложениями / Г. Г. Москвич. - СПб : Изд-во путеводителей Гр. Москвича, 1913. - 498 с.

4. Субботин, О. С. Архитектурно-исторические аспекты развития гостиниц Черноморского побережья России: конец XIX - первая половина XX в. / О. С. Субботин // Архитектура: сб. науч. тр. БНТУ. - Минск. - 2020. - Вып. 13. - С. 48-54.

5. Дороватовский, С. Сочи и Красная Поляна с окрестностями: путеводитель / С. Дороватовский. - Репр. воспр. изд. 1911 г. Краснодар : Платонов И., 2010. - 256 с.

6. История Сочи в открытках и воспоминаниях. Испр. и доп. Ч. І. Забытые страницы. Конец XIX - начала XX века. - Майкоп : ОАО «Полиграфиздат «Адыгея», 2007. - 136 с.

7. Артюхов, С. А. Сочи. На рубеже XIX - XX веков. Почтовая открытка / С. А. Артюхов. - Москва : Интербук-бизнес, 2014. - 80 с.

8. Субботин, О. С. Архитектурно-планировочное наследие Сочи / О. С. Субботин // Жилищное строительство. - 2012. - № 5. - С. 48-51.

9. Субботин, О. С. Становление и развитие архитектурно-пространственной среды г. Темрюка Краснодарского края / О. С. Субботин // Вестник Брестского государственного технического университета. - 2020. - №1(111): Строительство и архитектура. C. $134-137$

\section{References}

1. Gordon, K. A. Staryj Sochi konca XIX - nachala XX vekov: Literaturno-hudozhestvennoe izdanie / K. A. Gordon. - 2-e izd., ispr. i dop. Sochi: ZAO «Doriya», 2005. - $164 \mathrm{~s}$.

2. Enciklopedicheskij slovar' / pod red. K. K. Arsen'eva, E. E. Petrushevskogo [i dr.]. - SPb. : Tipografiya akc. obshch. «lzdatel'skoe Dtlo», Brokgauz"-Efron", 1901. - T. XXXIIA. - $960 \mathrm{~s}$

3. Moskvich, G. G. Illyustrirovannyj putevoditel' po Kavkazu s prilozheniyami / G. G. Moskvich. - SPb : Izd-vo putevoditelej Gr. Moskvicha, 1913. $-498 \mathrm{~s}$.

4. Subbotin, O. S. Arhitekturno-istoricheskie aspekty razvitiya gostinic CHernomorskogo poberezh'ya Rossii: konec XIX - pervaya polovina XX v. / O. S. Subbotin // Arhitektura: sb. nauch. tr. BNTU. - Minsk. 2020. - Vyp. 13. - S. 48-54.

5. Dorovatovskij, S. Sochi i Krasnaya Polyana s okrestnostyami: putevoditel' / S. Dorovatovskij. - Repr. vospr. izd. 1911 g. - Krasnodar : Platonov I., 2010. - $256 \mathrm{~s}$.

6. Istoriya Sochi v otkrytkah i vospominaniyah. Ispr. i dop. CH. I. Zabytye stranicy. Konec XIX - nachala XX veka. - Majkop : OAO «Poligrafizdat «Adygeya», 2007. - $136 \mathrm{~s}$.

7. Artyuhov, S. A. Sochi. Na rubezhe XIX - XX vekov. Pochtovaya otkrytka / S. A. Artyuhov. - Moskva : Interbuk-biznes, 2014. - 80 s.

8. Subbotin, O. S. Arhitekturno-planirovochnoe nasledie Sochi / O. S. Subbotin // ZHilishchnoe stroitel'stvo. - 2012. - № 5. - S. 48-51.

9. Subbotin, O. S. Stanovlenie i razvitie arhitekturno-prost-ranstvennoj sredy g. Temryuka Krasnodarskogo kraya / O. S. Subbotin // Vestnik Brestskogo gosudarstvennogo tekhnicheskogo universiteta. - 2020. №1(111): Stroitel'stvo i arhitektura. - S. 134-137.

Материал поступил в редакцию 24.11.2020 